\title{
EL PROCESO DE CREACIÓN DE DERECHO
}

\author{
Rafael Hernández Marín
}

Universidad de Murcia

\section{Introducción}

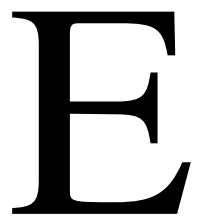

1 proceso que comienza con la elaboración de un documento y finaliza con la conversión de dicho documento en Derecho atraviesa diversas etapas. En muchas de ellas, el documento va adquiriendo nuevas propiedades que la doctrina describe en unos términos que me parecen sumamente insatisfactorios.

Así, hay autores que dicen y repiten que un documento aprobado por las Cortes Generales es una Ley, o sale de esa fase convertido ya en Ley. Aunque también afirman, con la misma insistencia, que la publicación es un requisito necesario para la existencia de una Ley. ¿Acaso la contradicción no es evidente?

Otras veces, la afirmación de que un documento aprobado por las Cortes es una Ley, o incluso una disposición jurídica, va acompañada de la tesis de que la sanción del Jefe del Estado perfecciona esa Ley, y la publicación le añade una perfección ulterior; perfección que, según algunos autores, alcanza el grado sumo con la entrada en vigor. Con ello se quiere decir que, aunque al ser aprobado por las Cortes adquiera la cualidad de ser Ley, el documento va perfeccionando dicha cualidad en las fases sucesivas de sanción, publicación y entrada en vigor. Sin embargo, la cualidad de ser Ley no es graduable: un documento o es o no es una Ley, en términos absolutos; $\mathrm{y}$, dados dos documentos que sean Leyes (cualesquiera que sean los requisitos que sean exigidos para que algo sea una Ley), ninguno de ellos tiene la cualidad de ser Ley con mayor perfección, o en mayor medida, que el otro, ni con mejor título que el otro.

También llaman la atención las propiedades que, según se dice, adquiere un documento a lo largo de las diversas etapas del proceso de creación de Derecho: ejecutoriedad, fuerza vinculante, obligatoriedad, validez, eficacia, aplicabilidad, vigencia, etc. Y a ello hay que añadir que algunas de estas propiedades a veces se poseen por partida doble (se habla, por ejemplo, de la «doble ejecutoriedad» de una Ley); otras comprenden subespecies (se 
distingue a veces entre validez formal y validez material); y otras, finalmente, admiten graduación (se habla, por ejemplo, de la «eficacia intermedia» de una Ley). Pero, en realidad, muchos de los términos citados no expresan propiedades. Por ejemplo, si decir que una Ley es obligatoria o aplicable significa que la Ley debe ser cumplida o debe ser aplicada, ni «es obligatoria», ni «es aplicable» expresarían propiedades; de la misma manera que «debe ser generoso» no expresa ninguna propiedad de Pedro, al decir «Pedro debe ser generoso». Por lo demás, no es fácil saber cuáles de aquellos términos son sinónimos, ni qué diferencias semánticas o relaciones hay entre ellos, a pesar de que son manejados como términos familiares, que no necesitan ninguna aclaración.

La exposición que sigue está dividida en dos partes. En la primera, expreso mis opiniones respecto a: a) qué etapas o aspectos del proceso de creación de Derecho son relevantes para la conversión de un documento en Derecho y cuáles no; y b) qué ocurre en esas etapas. En la segunda parte, expongo las dificultades que existen para identificar un documento como Derecho y algunas consecuencias que se derivan de dichas dificultades.

\section{Cuerpos legales y cuerpos jurídicos}

1. El término «Resolución del Rectorado de la Universidad de Salamanca» es usado para significar un documento firmado por el Rector de la Universidad de Salamanca, y en cuyo encabezamiento figura la expresión «Resolución». Análogamente se entiende el término «Orden Ministerial»: como un documento firmado por un Ministro, y en cuyo encabezamiento figura la expresión «Orden».

Las cosas son distintas, al menos parcialmente, con el término «Decreto del Gobierno». Por «Decreto del Gobierno» se entiende un documento en cuyo encabezamiento aparece la expresión «Decreto», y que presenta otras características recogidas en ciertos enunciados jurídicos. Por ejemplo, atendiendo al art. 62 f) de la Constitución, los Decretos del Gobierno son documentos acordados por el Consejo de Ministros y que están expedidos por el Rey.

Con el término «Ley», en el ámbito jurídlco, ocurre algo parecido que con el término «Decreto del Gobierno». Por «Ley» se entiende un documento en cuyo encabezamiento aparece la expresión «Ley», y que presenta otros rasgos recogidos en ciertos enunciados jurídicos, concretamente, en los enunciados constitucionales que regulan el proceso legislativo. Por ejemplo, conforme a dichos enunciados, condición necesaria para que un documento sea una Ley es que dicho documento haya sido aprobado por las Cortes Generales. 
2. La exposición anterior es, naturalmente, una simplificación de la realidad: no tiene en cuenta la posibilidad de delegación, ni la necesidad de refrendar el acto del Rey de expedir un Decreto, omite pronunciarse, con relación a las Leyes, sobre la importancia de la sanción y de la promulgación, etc.

Sin embargo, es suficiente para destacar los puntos siguientes:

A) Los documentos citados son, todos ellos, cuerpos legales. Y cualquier categoría de cuerpos legales, por ejemplo, la de los Decretos del Gobierno, puede ser definida mediante una serie de predicados $F_{1}, F_{2}, \ldots, F_{n}$, que expresen los rasgos que consideramos necesarios y, conjuntamente, suficientes para calificar algo como un Decreto del Gobierno.

B) En la creación de un cuerpo legal cualquiera C, pueden ser cometidas «irregularidades» de cuatro clases:

1) La primera consiste en que la creación de $C$ haya sido infringido un enunciado jurídico prescriptivo $E$ que regula la creación de los cuerpos legales de la misma categoría que $C$.

Supongamos que $C$ es una Ley, y $E$, un enunciado jurídico prescriptivo que regula la creación de las Leyes, por ejemplo, el art. 88 de la Constitución (que ordena que el Gobierno adjunte una exposición de motivos y unos «antecedentes» a los proyectos de Ley que someta al Congreso). $C$ sería irregular, si ha sido creada infringiendo este enunciado.

2) La segunda forma de irregularidad consiste en que $C$ contenga algún enunciado $E_{l}$ que sea incorrecto según algún enunciado jurídico $E$ cualificatorio (de rango jerárquico superior a $E_{l}$ ).

Sea $E$ el art. 25.3 de la Constitución, que establece que la Administración civil no puede imponer sanciones privativas de libertad. Según he sostenido en otro lugar, éste es un enunciado cualificatorio que significa lo siguiente: «Los enunciados creados por la Administración civil y que impongan sanciones privativas de libertad son incorrectos».

Supongamos, por otra parte, que $C$ es una Orden Ministerial y contiene un enunciado $E_{l}$, que castiga ciertas infracciones graves de la normativa reguladora de la caza o la pesca con una pena privativa de libertad. En este caso, diríamos que $E_{l}$ (al ser un enunciado creado por la Administración civil y que impone una sanción privativa de libertad) es un enunciado incorrecto según $E$ (según el art. 25.3 de la Constitución). Por esta razón, $E_{l}$ sería un enunciado irregular, en un segundo sentido del término «irregular».

3) La tercera forma de irregularidad consiste en que $C$ contenga algún enunciado $E_{l}$ que sea contrario a algún enunciado jurídico $E$ (de rango jerárquico superior a $\left.E_{l}\right)$.

Dejaré a un lado la delicada cuestión de determinar cuándo dos enunciados legales son contrarios (y también el problema de la jerarquía norma- 
tiva). E1 punto que deseo señalar en este momento es que existe una tercera forma de irregularidad, que hay que distinguir de las dos clases anteriores, especialmente, de la segunda de ellas.

Pues sea $C$ una Ley. Y sea $E_{l}$ un enunciado, contenido en $\mathrm{C}$, que establece que los Delegados del Gobierno pueden (en ciertos casos) imponer sanciones privativas de libertad. Este enunciado $E_{l}$ sería contrario, en un sentido plausible del término «contrario», al enunciado $E$ del último ejemplo (al art. 25.3 de la Constitución). Por ello, sería un enunciado irregular, en un tercer sentido de este término.

4) Existe aún una cuarta forma posible de irregularidad. $C$ sería irregular, en este último sentido, si contuviera un enunciado $E_{l}$, cuya creación (dicho brevemente) no hubiera sido autorizada por ningún enunciado jurídico $E$, esto es, un enunciado $E_{l}$ tal que no existe un enunciado jurídico $E$ según el cual $E_{l}$ es correcto.

$C$ podría ser, por ejemplo, una Resolución del Rectorado de la Universidad de Salamanca, y $E_{l}$, un enunciado, contenido en $C$, que establece que todos los miembros de dicha Universidad deben vacunarse de la gripe antes del comienzo del curso académico. De este enunciado $E_{l}$ diríamos que no existe ningún enunciado jurídico $E$ que autorice su creación, o que no existe ningún enunciado jurídico $E$ según el cual $E_{1}$ es correcto.

Mientras que la segunda forma de irregularidad del cuerpo legal $C$, antes descrita, consiste en que según el Derecho (según un enunciado jurídico $E$ ) el enunciado $E_{l}$, contenido en $C$, es incorrecto, esta última forma de irregularidad consiste en que no sucede que según el Derecho (según algún enunciado jurídico $E$ ) el enunciado $E_{l}$, contenido en $C$, es correcto.

La primera forma de irregularidad que ha sido descrita afecta a todos los enunciados contenidos en $C$. En cambio, las tres últimas sólo afectan al enunciado $E_{l}$.

C) La terminología legal y doctrinal que suele ser usada para aludir a los cuatro tipos de casos que acaban de ser diferenciados no es precisa, ni uniforme, ni tampoco distingue entre dichos casos. En cualquiera de los tres primeros casos, se diría (utilizando los términos que aparecen en la Ley Orgánica del Tribunal Constitucional, arts. 27, 28, 33, 35, etc.) que el cuerpo legal $C$ es «disconforme» con el enunciado jurídico $E$, o lo «infringe», o es «contrario» a él. En el último caso de irregularidad descrito, es posible que se afirme que $E_{l}$ o $C$ no es conforme con el Derecho, o lo infringe o es contrario a él.

Esta terminología debería ser sustituida por otra más refinada. Pues, por ejemplo, de infracción sólo cabe hablar, en rigor, en el primer tipo de irregularidad. Y, por muy ampliamente que se entienda el término «contrario», 
éste no puede o no debe cubrir los tres primeros tipos irregularidad que han sido diferenciados, y en ningún caso el cuarto.

Sin embargo, ese refinamiento de la terminología queda al margen de los objetivos del presente trabajo ${ }^{1}$. Para dichos objetivos, es suficiente hablar genérica y vagamente de «irregularidad»; y, cuando sea necesario, precisar de qué tipo de irregularidad se trata.

D) Paralelamente a las cuatro formas de irregularidad que acaban de ser diferenciadas, podemos distinguir cuatro formas de regularidad. Y la primera tesis del presente trabajo que deseo destacar es que, para que un documento sea un cuerpo legal, de cualquier categoría, no es preciso que sea regular, en ninguno de los cuatro sentidos del término «regular».

O dicho de otra manera: para que un documento sea, por ejemplo, un Decreto del Gobierno, es preciso que haya sido acordado por el Gobierno. Un Decreto del Gobierno que no haya sido acordado por el Gobierno es imposible; no es en realidad un Decreto del Gobierno. Pero un Decreto del Gobierno irregular, en cualquiera de los cuatro sentidos del término «irregular», es perfectamente posible; no por ser irregular deja de ser un Decreto del Gobierno. Entre los predicados $F_{1}, F_{2}, \ldots, F_{n}$, que definen el término «Decreto del Gobierno», no figura el término «es regular».

Del mismo modo, para que un documento sea una Ley (en la España actual, naturalmente), es preciso que haya sido aprobado por las Cortes Generales; pero no es preciso que sea regular, en ninguno de los cuatro sentidos del término «regular». Una Ley no aprobada por las Cortes no es una Ley; pero una Ley irregular sí lo es. Entre las propiedades cuya presencia en un documento es necesaria y, conjuntamente, suficiente para que califiquemos dicho documento como una Ley se halla el haber sido aprobado por las Cortes; pero no se halla el ser regular, en ninguno de los cuatro sentidos. Éstas son consecuencias del uso corriente del término «Ley».

3. Conviene, en este momento, detenerse a examinar el caso particular de las Leyes, para determinar si los actos de sanción y promulgación de las Leyes por el Jefe del Estado son necesarios para la existencia de un cuerpo legal de dicha categoría.

Comencemos examinando la promulgación. Ésta, en cuanto acto de certificación (o de notificación, según algunos autores) de la existencia de una Ley, presupone conceptualmente que la Ley existe previamente al acto de promulgar. De ahí que la promulgación no sea un elemento constitutivo de la Ley.

${ }^{1}$ Un intento en este sentido es el de Riccardo GUASTINI: Il giudice e la legge, G. Giappichelli, Torino, 1995, pp. 146-154. 
Por lo que respecta a la sanción, y al margen de que una sanción sin la contrapartida de la posibilidad de veto, como es el caso actualmente en España, dudosamente merece tal nombre, hay un dato que considero determinante. Se trata de que, en la España actual, la sanción se identifica con las palabras «vengo en sancionar», que el Jefe del Estado expresa incrustadas en la fórmula de promulgación. De manera que la sanción y la promulgación son actos simultáneos. Luego si un documento era una Ley antes de ser promulgado, también lo era antes de ser sancionado. De lo cual se deduce que tampoco la sanción es necesaria para la existencia de una Ley.

Así, pues, antes de ser sancionado y promulgado por el Jefe del Estado, el documento que es aprobado por las Cortes con el título de «Ley» ya es una Ley, esto es, un cuerpo legal de la categoría de las Leyes.

4. La segunda tesis que deseo destacar es que, para que un documento sea un cuerpo legal de cualquier categoría, tampoco es preciso que haya sido publicado. Una Resolución del Rectorado de la Universidad de Salamanca no publicada es una Resolución del Rectorado de la Universidad de Salamanca; no carece de dicha cualidad por no haber sido publicada. Del mismo modo, una Ley no publicada también es una especie de Ley, no una especie de no Ley. Para que un documento sea una Ley ha de ser aprobado por las Cortes Generales, pero no es preciso que sea publicado.

Así lo consideran incluso los autores que, en teoría, afirman que la publicación es condición necesaria para que un documento sea una Ley o para la perfección de una Ley. Pero, en la práctica, cuando comentan algún caso (de la época franquista) de Leyes no publicadas, ninguno de dichos autores afirma que tales documentos no eran, o no eran realmente, Leyes.

Creo, en definitiva, que los dos únicos aspectos que de hecho tenemos en cuenta para identificar un documento como un cuerpo legal de una determinada categoría son su encabezamiento (que en él aparezca la palabra «Ley», o «Decreto», etc.) y el órgano que lo expide o aprueba.

5. La tercera y última tesis a destacar, que es la tesis central de este trabajo, es la siguiente: un cuerpo jurídico es un cuerpo legal que ha sido publicado (rectifico así la identificación, que he realizado en obras anteriores, entre cuerpos legales y cuerpos jurídicos).

Esta tesis presupone en cierto sentido que la publicación no es necesaria para la existencia de un cuerpo legal. Y afirma que, dado un documento que sea un cuerpo legal, para su conversión en un cuerpo jurídico es necesario y suficiente que sea publicado.

Esto es precisamente lo que sucede con los tratados internacionales, según el art. 96.1 de la Constitución y el art. Código Civil. Antes de ser publicados, los tratados existen como cuerpos legales (y quizá también como cuerpos jurídicos del ordenamiento jurídico internacional). Pero, para su in- 
corporación al ordenamiento jurídico español, para su conversión en cuerpos jurídicos españoles, es condición necesaria y suficiente, según los artículos que acaban de ser citados, que sean publicados en el Boletín Oficial del Estado.

6. La que acabo de denominar «tesis central» del presente trabajo tiene las dos consecuencias siguientes:

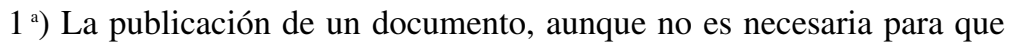
éste se convierta en un cuerpo legal, sí es necesaria para que se convierta en un cuerpo jurídico. Comparto pues la opinión, aceptada por la doctrina de forma casi unánime, según la cual la publicación es condición necesaria de juridicidad. (Entre las escasas voces discordantes con dicha opinión figuran las de los filósofos del Derecho más influyentes de la segunda mitad del siglo XX, como H. Kelsen, A. Ross y H.L.A. Hart, los cuales no mencionan la publicación como requisito para que algo sea Derecho.)

Antes de la publicación, tenemos un cuerpo legal, por ejemplo, de la categoría de las Órdenes Ministeriales o de las Leyes. Pero ello no es aún un cuerpo jurídico; todavía no se ha creado Derecho.

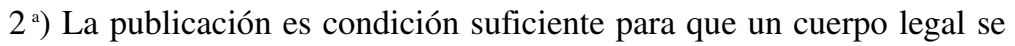
convierta en un cuerpo jurídico.

Al ser publicado, el documento que previamente era ya un cuerpo legal de la categoría de las Órdenes Ministeriales (o de las Leyes) se convierte en Derecho, concretamente, se convierte en un cuerpo jurídico de esa misma categoría de las Órdenes Ministeriales (o de las Leyes). Con la publicación, un cuerpo legal de la categoría de las Órdenes Ministeriales (o de las Leyes) se incorpora al ordenamiento jurídico.

7. Un cuerpo jurídico puede ser irregular en los mismos cuatro sentidos en que puede serlo un cuerpo legal.

Pues sea $C$ un cuerpo legal irregular. Cuando es publicado, $C$ continúa siendo un cuerpo legal irregular, dado que la publicación no subsana, obviamente, dicha irregularidad. Por otra parte, y según se acaba decir, la publicación es condición suficiente para que un cuerpo legal se convierta en un cuerpo jurídico.

Por ello, al ser publicado, el cuerpo legal $C$ se convierte en un cuerpo jurídico, a pesar de su irregularidad. En consecuencia, $C$, que ya era un cuerpo legal irregular, con la publicación se convierte además en un cuerpo jurídico irregular, en el mismo sentido en que era y es un cuerpo legal irregular.

Mas existe una forma ulterior de irregularidad que puede afectar a los cuerpos jurídicos, aunque no a los documentos que sean meramente cuerpos legales. Se trata de una irregularidad cometida en el proceso de conversión de un cuerpo legal en un cuerpo jurídico, esto es, en el proceso que comienza una vez que el cuerpo legal ya existe y finaliza en el momento de la 
publicación del cuerpo legal. Aunque tampoco esta forma adicional de irregularidad de los cuerpos jurídicos afecta a su condición de cuerpos jurídicos (dado que la publicación es condición suficiente para que un cuerpo legal se convierta en un cuerpo jurídico).

Esta quinta forma de irregularidad es análoga a la primera forma de irregularidad de los cuerpos legales. Consiste en que un cuerpo jurídico $C$ haya sido creado infringiendo alguno de los enunciados jurídicos prescriptivos que regulan la creación de los cuerpos jurídicos de la misma categoría que $C$.

Por ejemplo, un cuerpo legal que sea una Ley puede haber sido creado infringiendo el art. 88 de la Constitución antes citado, que regula la creación de los cuerpos legales de la categoría de las Leyes. Se trataría entonces de una Ley irregular (irregular en el primer sentido). Y algo análogo puede suceder en el caso de un cuerpo jurídico que sea una Ley, esto es, en el caso de una Ley publicada. Pues puede ocurrir que la creación de dicho cuerpo jurídico, su publicación, haya tenido lugar infringiendo un enunciado jurídico prescriptivo, como el art. 91 de la Constitución, que regula la creación de los cuerpos jurídicos de la categoría de las Leyes. Puede ocurrir, dicho más claramente, que ese cuerpo jurídico de la categoría de las Leyes no haya sido sancionado o promulgado por el Jefe del Estado; o también que éste, el Rey, no haya ordenado su publicación (y que la Ley haya sido publicada a instancia de otro órgano). En cualquiera de estos casos, también estaríamos ante una Ley irregular (irregular en el quinto sentido).

8. Cabría pensar en considerar la regularidad como una condición necesaria para que un documento se convierta en un cuerpo jurídico o meramente en un cuerpo legal. Cabría argüir, por ejemplo, que entre los predicados $F_{1}, F_{2}, \ldots, F_{\mathrm{n}}$, que definen una categoría cualquiera de cuerpos legales, se halla el término «es regular».

Sin embargo, esta tesis tropieza con dificultades teóricas y prácticas:

Desde el punto de vista teórico, son conocidas las dificultades que existen para integrar la noción de regularidad (especialmente, la regularidad en el cuarto sentido) en el concepto de «norma jurídica»; ${ }^{2}$ y las mismas dificultades encontraríamos al intentar considerar la regularidad como condición necesaria para la existencia de un cuerpo legal o jurídico de cualquier categoría. Al margen de ello está la circunstancia de que, de hecho, no consideramos la regularidad como condición necesaria para la existencia de un cuerpo legal. Calificamos un documento como Orden Ministerial, Decreto

${ }^{2}$ Véase al respecto José Juan MORESO: «Sobre normas inconstitucionales», en José Juan Moreso: Normas jurídicas y estructura del Derecho, México, Distribuciones Fontamara, 1997, pp. 59-100. 
del Gobierno, etc., con independencia de que sea o no regular, sin examinar su contenido, ni preguntarnos cómo ha sido creado.

Desde el punto de vista práctico, considerar la regularidad como condición necesaria para que un cuerpo legal exista también conlleva dificultades. Pues determinar si un documento es o no regular exige un conocimiento del Derecho más que mediano; conocimiento que no está al alcance de la mayoría de los ciudadanos. Por lo cual, éstos no podrían determinar si algo es o no un cuerpo legal, en el caso de que los cuerpos legales fueran definidos mediante la nota de regularidad.

Mas, aunque la irregularidad de un documento no afecte a su carácter de cuerpo legal, ni a su carácter de cuerpo jurídico, ello no significa que para un cuerpo legal o jurídico sea indiferente el ser irregular. Pero la trascendencia jurídica que tenga la irregularidad de un cuerpo legal o jurídico no es consecuencia de la irregularidad per se. La trascendencia jurídica de este fenómeno, al igual que la de cualquier otro fenómeno, depende de las consecuencias que ciertos enunciados jurídicos, si los hay, atribuyan a la irregularidad o a un tipo concreto de irregularidad. Puede ser que existan enunciados jurídicos, como el del art. 1.2 del Código Civil, según el cual carecen de «validez las disposiciones que contradigan otra de rango superior»; o como el del art. 6.3 del mismo código, que declara «nulos de pleno Derecho» los «actos contrarios a las normas imperativas y prohibitivas»; pero también puede ocurrir que no existan tales enunciados. Y también es una cuestión contingente la existencia o no de recursos, como el de inconstitucionalidad o el contencioso-administrativo, tendentes a remediar unas u otras irregularidades de los cuerpos jurídicos.

9. Por lo que respecta a la fecha de entrada en vigor, ésta es irrelevante tanto para la conversión de un documento en un cuerpo legal, como para su conversión en un cuerpo jurídico. Es más, como creo haber mostrado en otro lugar ${ }^{3}$, con la llegada de la fecha de entrada en vigor, un documento, un cuerpo legal o jurídico, no adquiere ninguna nueva propiedad que antes no tuviera, ni siquiera la vigencia. Según sostengo en la obra que acabo de citar, la fecha de entrada en vigor sólo es relevante para lo que en dicha obra denomino «intervalos de referencia» de los enunciados jurídicos, sobre todo para el intervalo de subsunción.

10. La publicación de un cuerpo legal, además de convertir a éste en un cuerpo jurídico, también convierte en jurídicos a todos los enunciados contenidos en él.

Es posible describir, de esta manera, el proceso de creación de Derecho, de forma coherente y sin necesidad de recurrir a términos como los citados

${ }^{3}$ En Introducción a la teoría de la norma jurídica, Madrid, Marcial Pons, 1998, pp. 433-448. 
al inicio: «obligatoriedad», «validez», «vigencia», etc. Ello no sólo es posible, sino también conveniente. Pues ni la fuerza vinculante, ni la obligatoriedad existen; los enunciados jurídicos ni tienen fuerza vinculante, ni es obligatorio cumplirlos (normalmente, no existen normas que ordenen cumplir los enunciados jurídicos, ni es necesario que tales normas existan). Por otro lado, hablar de vigencia o de intervalo de vigencia es fruto de una confusión. «Validez» es un término ambiguo: un enunciado válido es tanto un enunciado jurídico, simplemente, como un enunciado que se considera obligatorio, como lo que aquí llamaríamos un enunciado regular, especialmente, regular en el cuarto sentido. La aplicabilidad, en cualquiera de las dos acepciones plausibles de dicho término, no tiene nada que ver con el proceso de creación del Derecho: un enunciado jurídico puede ser aplicable, en cualquiera de los dos sentidos, a casos ocurridos antes de que el enunciado fuera legal y jurídico, y también a casos ocurridos después de que el enunciado haya dejado de ser jurídico. «Eficacia» también es un término ambiguo, que igual quiere decir «obligatoriedad», que «vigencia», que «aplicabilidad». Por último, en cuanto a «ejecutoriedad», no veo qué cosa distinta de todas las anteriores pueda significar ${ }^{4}$.

\section{La publicación: originales y copias}

1. Venimos considerando los cuerpos legales como documentos, esto es, como textos escritos en papel (o inscritos en cualquier otro soporte físico). Pero es posible que se objete que algunos cuerpos legales no son textos escritos, sino orales. Para hacer frente a esta eventualidad, manteniendo la tesis de que los cuerpos legales son documentos, podemos entender el término «documento» ampliamente, para comprender tanto un texto escrito, como un texto oral. Documentos orales (sean o no cuerpos legales) serían un acuerdo verbal adoptado por un órgano colegiado, un contrato verbal, un discurso o charla, etc.

Para que un documento, escrito $u$ oral, que es un cuerpo legal sea un cuerpo jurídico, es preciso que sea publicado, es decir, es preciso que sean difundidas de forma oficial copias de dicho documento (pues en esto consiste la publicación). En la actualidad, dichas copias son textos escritos que aparecen en boletines oficiales (en otra época, y quizá todavía en algún caso excepcional, algunas copias eran o son textos orales, por ejemplo, pregones).

Si el cuerpo legal es un documento escrito, es posible enviar el propio cuerpo legal a un boletín oficial para su publicación. Pero si el cuerpo legal

${ }^{4}$ Sobre estas cuestiones, me remito a la misma obra mía citada en la nota anterior (pp. 258265, 291-294, 433-448). 
es un documento oral, sólo es posible enviar a un boletín oficial, con vistas a su publicación, una copia escrita del cuerpo legal. Aunque también cuando el cuerpo legal es un texto escrito lo que se envía en ocasiones a un boletín oficial para ser publicado es una copia del cuerpo legal, no éste mismo.

En cualquier caso, cuando lo que se envía a un boletín oficial es una copia del cuerpo legal, ésta va firmada por alguien que da fe de que dicha copia reproduce fielmente el contenido del documento original. Esto sucede, por ejemplo, en el caso de las Leyes. A1 Boletín Oficial del Estado se envía una copia de una Ley, copia que va firmada por el Jefe del Estado, quien certifica, mediante el acto de promulgación, que dicha copia reproduce fielmente el contenido de un cuerpo legal de la categoría de las Leyes.

Una vez que el cuerpo legal, o bien una copia suya autorizada, llega a uno de los organismos oficiales que gestionan un boletín oficial, éstos imprimen, en los diversos ejemplares de un número de dicho boletín, copias de los documentos que han recibido.

Mas la publicación de un cuerpo legal no finaliza con la impresión de copias suyas en los ejemplares de un boletín oficial. La publicación de un cuerpo legal consiste, como ya ha sido advertido, en la difusión o distribución oficial de copias de dicho cuerpo legal. Por ello, para cumplir el requisito de la publicación, no basta la impresión de copias de un cuerpo legal, sino que es preciso además difundir dichas copias impresas ${ }^{5}$. En la práctica, no obstante, consideramos como fecha de publicación de un cuerpo legal la fecha que aparece en el número del boletín en el que aparecen las copias de dicho cuerpo legal.

2. Conviene subrayar, antes de continuar con otros temas, que el cuerpo legal, el documento que es un cuerpo legal, y al ser publicado también un cuerpo jurídico, es el documento (escrito u oral) original, no sus copias impresas en los boletines oficiales. La impresión de dichas copias y su posterior difusión convierten en jurídico un cuerpo legal, pero no son ellas mismas cuerpos legales o jurídicos.

Pues tratándose, por ejemplo, de Decretos del Gobierno, condición necesaria para que un documento sea un Decreto del Gobierno es que haya sido expedido por el Rey. Mas el Rey no expide las copias impresas en el Boletín Oficial del Estado. De ahí que dichas copias no sean Decretos del Gobierno. J.A. Santamaría Pastor escribe, en el mismo sentido, que «Ley es lo

\footnotetext{
${ }^{5}$ Véase al respecto Hans-Joachim HALLIER: «La promulgation et la publication des lois et reglements dans la République Fédérale d'Allemagne», en Jacques-Bernard Herzog et Georges Vlachos: La promulgation, la signature et la publication des textes législatifs en droit comparé, Les Éditions de L'Epargne, Paris, 1961, pp. 13-39, pp. 26-27; y Georges VLACHOS: «Promulgation et publication des textes législatifs en droit constitutionnel hellénique», en Jacques-Bernard Herzog et Georges Vlachos: La promulgation ..., cit., pp. 107-140, pp. 127-128.
} 
que las Cámaras legislativas realmente aprueban..., no lo que el tipógrafo del Boletín Oficial hace o decide» ${ }^{6}$.

De no ser así habría que considerar como órganos jurídicos, como órganos creadores de Derecho, a las personas que trabajan en las imprentas de los boletines oficiales o incluso de las editoriales privadas. Una conclusión absurda, desde el punto de vista de cualquier teoría. Aunque ésta es precisamente la tesis que intenta imponer el art. 4.1 del Real Decreto 1511/1986, de 6 de junio, de Ordenación del Diario Oficial del Estado, al decir lo siguiente: «El texto de las disposiciones, resoluciones y actos publicado en el "Boletín Oficial del Estado" tiene la consideración de oficial y auténtico».

3. Los cuerpos legales (originales) no están físicamente accesibles a los ciudadanos. Es más, ni siquiera están jurídicamente accesibles. Pues el art. 15.3 del Real Decreto que acaba de ser citado establece que los documentos «originales recibidos para publicación en el Diario Oficial del Estado tendrán carácter reservado y no podrá facilitarse información acerca de ellos».

En mi opinión, es una perversión impedir (física o jurídicamente) a los ciudadanos de un país que conozcan de forma directa el Derecho de su país, y forzarles a conocer su Derecho a través de un organismo gestionado por el poder ejecutivo. Mas, al margen de su valoración, esta circunstancia origina que los ciudadanos no puedan saber si un documento es o no Derecho, ya que los documentos que presuntamente son Derecho son inaccesibles para ellos.

4. Es cierto que lo importante para los ciudadanos no es conocer directamente los documentos que son cuerpos jurídicos, sino el contenido de éstos; y que ésta es precisamente la función que realiza la publicación.

Sin embargo, los ciudadanos no pueden tener certeza de que lo impreso en un boletín oficial reproduce fielmente el contenido de un cuerpo legal más que consultando éste. Pero esto no es posible, según acabamos de ver.

En teoría, una alternativa sería que alguien diera fe, mediante su firma, de que las copias impresas en los distintos ejemplares de un número de un boletín oficial reproducen fielmente el contenido de un documento, cuerpo legal, original. Sin embargo, en la práctica, ello no es posible. Pues ya sería un trabajo arduo que una persona firmara, por ejemplo, las miles de copias de una determinada Orden Ministerial contenidas cada una de ellas en un ejemplar distinto de un número del BOE, para testimoniar que cada una de dichas copias es conforme con el documento original de la Orden. Pero es que además lo mismo habría que hacer con las copias de todas las Órdenes

${ }^{6}$ Juan Alfonso SANTAMARÍA PASTOR: Fundamentos de Derecho Administrativo, I, Madrid, Centro de Estudios Ramón Areces, 1988, p. 366. 
Ministeriales, así como con las copias de las Leyes, los Decretos, Resoluciones, etc., contenidas en esos mismos ejemplares del BOE que contienen las copias de la citada Orden Ministerial. Lo que exigiría que los mismos miles de ejemplares de un mismo número del BOE fueran firmados por decenas de personas, a veces alejadas unas de otras por cientos o miles de kilómetros.

Sin embargo, la imposibilidad de realizar esta tarea no debe hacernos olvidar cuál es su consecuencia:

En el tráfico jurídico, necesitamos muchas veces aportar, por ejemplo, una escritura pública o una Sentencia judicial. Y dado que los documentos originales no están disponibles para los ciudadanos, sustituimos el documento original de la escritura o de la Sentencia por una copia. Pero, frecuentemente, se nos exige que esta copia esté firmada por algún fedatario público que dé fe o testimonio de que dicha copia es conforme con la escritura o Sentencia original. En el caso de una Ley (o un Decreto, etc.), el documento original de la Ley tampoco está disponible para los ciudadanos. Pero en este caso, en cambio, nunca es preciso que nadie aporte una copia de una Ley firmada por alguien que dé fe de que dicha copia es conforme con el documento original de la Ley. Ello es así porque, como se ha dicho, las copias de las Leyes no son firmadas por nadie, ni siquiera las que aparecen en el BOE, dado que es prácticamente imposible hacerlo. Pero llama la atención los escrúpulos existentes en el caso de una escritura pública o de una Sentencia, y la ausencia total de escrúpulos en el caso, sin duda más trascendente, de una Ley.

5. Consecuencia de las observaciones anteriores es que los ciudadanos no tienen seguridad, ni ninguna garantía de que el texto de un boletín oficial es una copia de un cuerpo legal, ni siquiera de un documento. Por ello, la difusión de un boletín oficial no asegura, ni garantiza a los ciudadanos la publicación de un cuerpo legal o documento.

El resultado es que los criterios que definen lo que es un cuerpo jurídico (un cuerpo legal publicado) no pueden ser aplicados por los ciudadanos para determinar si un documento es o no un cuerpo jurídico. (Esta dificultad para aplicar los criterios que definen lo que es Derecho es una dificultad meramente jurídica o política, pero no conceptual, como la expuesta en el apartado II.8.)

Por todo ello, lo que sucede en la práctica es que, cuando leemos en un boletín oficial un texto, los ciudadanos suponemos lo siguiente:

$1^{\circ}$ ) Que existe un documento anterior al texto del boletín y que éste sólo es una copia fiel de aquel documento previo. Suponemos que el contenido del texto del boletín oficial no se lo han inventado, ni siquiera parcialmente, en el organismo que gestiona dicho boletín. 
A partir de esta suposición (y de la difusión del boletín), podemos concluir que el documento previo ha sido publicado, esto es, que han sido difundidas de manera oficial copias de dicho documento.

$2^{\circ}$ ) Que ese documento previo u original, cuya existencia suponemos al leer el boletín, reúne todas las características que son necesarias para ser un cuerpo legal de una determinada categoría.

El resultado es, en definitiva, que un texto impreso en un boletín oficial nos hace suponer que existe un documento original, con idéntico contenido al del texto del boletín, y que reúne los dos requisitos que son necesarios para que dicho documento se haya convertido en un cuerpo jurídico: el requisito de ser un cuerpo legal y el requisito de la publicación.

Algo análogo sucede con la fecha del boletín oficial en el que aparece impreso un texto. Suponemos que dicha fecha, que consideramos como fecha de publicación o difusión de las copias que aparecen en el boletín, es la fecha de publicación de un documento original que es un cuerpo legal, y cuyo contenido es igual al del texto del boletín.

6. La fecha de publicación de un cuerpo legal tiene una doble trascendencia, dado que de ella dependen dos fechas: la fecha de la conversión del cuerpo legal en un cuerpo jurídico y (conforme al art. 2.1 del Código Civil) la fecha de entrada en vigor del cuerpo legal.

Pues, por un lado, y dado que un cuerpo jurídico es un cuerpo legal publicado, la fecha en la que un cuerpo legal se convierte en un cuerpo jurídico coincide justamente con la fecha de la publicación del cuerpo legal. De ahí la suposición de que la fecha del boletín oficial en el que aparece impreso un texto es la fecha en que un documento que es un cuerpo legal, y cuyo contenido es igual al del texto del boletín, se ha convertido en un cuerpo jurídico.

Por otra parte (y según el artículo del Código Civil citado hace un momento), la fecha de entrada en vigor de un cuerpo legal es veinte días después de la completa publicación del cuerpo legal, si no se dispone otra cosa. Por esta razón, suponemos que, si no se dispone otra cosa, veinte días después de la fecha del boletín oficial en el que aparece impreso un texto es la fecha de entrada en vigor de un documento que es un cuerpo legal y jurídico, y cuyo contenido es igual al del citado texto del boletín.

7. Las presunciones anteriores quedan refutadas cuando en un boletín oficial aparece una corrección de errores. Una corrección de errores: $a$ ) destruye la presunción que teníamos hasta entonces acerca de la existencia de un cuerpo jurídico con un determinado contenido; y $b$ ) crea una nueva presunción, similar a la primera y refutable al igual que ésta. 
La corrección de errores tiene consecuencias tanto respecto a la fecha de entrada en vigor, como en relación a la fecha de conversión de un documento en un cuerpo jurídico.

A) Por lo que respecta a la fecha de entrada en vigor, ésta depende, en el caso normal, de la fecha de la completa publicación del cuerpo legal (según dice el art. 2.1 del Código Civil). Y una corrección de errores evidencia que la fecha que habíamos tomado como fecha de completa publicación de un cuerpo legal $C$ no era tal en realidad; y que, por tanto, también era errónea la fecha que habíamos considerado como fecha de entrada en vigor de los enunciados de $C$.

Por otra parte, una corrección de errores relativa al cuerpo legal $C$ nos hace suponer que es la fecha de publicación de la corrección de errores la que es realmente la fecha de la completa publicación de $C$. Por tanto, es la fecha de la corrección de errores la que, según suponemos a partir de dicha fecha, determina en el caso normal la fecha de entrada en vigor de todos los enunciados $C$, incluidos aquellos enunciados no afectados por la corrección de errores. En consecuencia, en el caso normal, la fecha de entrada en vigor de todos los enunciados de $C$ será veinte días después de la fecha de publicación de la corrección de errores.

B) Algo parecido ocurre con la fecha de conversión de un cuerpo legal en un cuerpo jurídico. Aunque en relación a esta cuestión no exista ningún enunciado jurídico que diga cuál es dicha fecha, sí existe la teoría según la cual un cuerpo jurídico es un cuerpo legal publicado. Y un cuerpo legal publicado es un cuerpo legal completamente publicado. De donde se deduce que un cuerpo jurídico es un cuerpo legal completamente publicado. Una tesis en cierta medida compartida por quienes redactaron el art. 1.5 del Código Civil, relativo a los tratados internacionales. Pues, según este artículo, para que un tratado se convierta en un cuerpo jurídico español, es necesario y suficiente su «publicación íntegra» en el Boletín Oficial del Estado.

Por todo ello, una corrección de errores aparecida en un boletín oficial evidencia que el cuerpo legal en cuestión no había sido (completamente) publicado en la fecha en que creíamos. De ahí que debamos corregir la tesis, que hasta entonces nos parecía verdadera, de que el cuerpo legal era jurídico desde la fecha en la que lo creímos completamente publicado. A partir de la corrección de errores, la tesis que vamos a suponer verdadera es que es la fecha de la corrección de errores la fecha de la completa publicación del cuerpo legal y también, por tanto, la fecha de la conversión de éste en un cuerpo jurídico, y asimismo la fecha de conversión en jurídicos de los enunciados en él contenidos. 


\section{DOXA 23 (2000)}

